\title{
Pulsed Fluorescent X-Ray System With On-Line Digitizer and Data Processor
}

\author{
G. J. Berzins \\ J. E. Valencia \\ J.W. Gutierrez \\ F. McGirt \\ K. R. Moore
}




\title{
PULSEIJ FLUORESCENT X-RAY SYSTEM WITH ON-LI'NE DIGITIZER AND DATA PROCESSOR
}

\author{
by
}

\author{
G. J. Berzins, J. E. Valencia, J. W. Gutierrez, \\ F. McGirt, and K. R. Moore
}

\begin{abstract}
A pulsed source of monoenergetic $x$ rays has been constructed for applications in which a narrow energy band and a short burst are both important. The radiation source is a high-purity, selectable foil that emits fuorescent $x$ rays upon excitation by a bremsstrahlung pulse. A digitizer and a microcomputer are integrated into the system to aid operation and data processing. A general description, the more important system characteristics, and a few examples of applications are given.
\end{abstract}

\section{INIRODLCTIOR}

The production of monoenergetic $x$ rays from a bremsstrahlung source that illuminates a fluorescent target has been demonstrated earlier.' Most of the previous work has been done with dc sources and fairly inw end-point energies: little attention has been focused on pulsed systems. An advantage of dc operation is that single-photon ccunting caf be employed. resulting in accurate determinations of some important parameters such as intensity and beam purity. The advantage of low end-point energies resides in cross sections-the probability of absorption as opposed te scattering decreases with increasing incident photon energy. The two processes become of comparable importance in most targets as incident energy exceeds about $100 \mathrm{keV}$ ?

In some applications a well-defined. narrow energy band is important. In other cases, dc sources are difficult to use. and pulsed sources become very desirable. An example is the calibration of detectors with high dark currents. A second example is characterization of detectors whose response is not linear. is $\mathrm{x}$-ray energy dependent. and must be mapped over a large infut intensity range. Other examples include studies of transient phenomena either for their own sake or as a means to more complicated measurements. Many of the pulsed sources that are commonly available have been designed for radiographic applications. These sources typically generate brenisstrahlung radiation with end-point energy ranging from 0.1 to $3 \mathrm{MeV}$ and with target $\mathrm{K}-\mathrm{x}$ ray lines superposed on the continuum.

We have incorporated such a bremsstrahlung source into a pulsed, fluorescent $x$-ray systen intended primarily to characterize the response of detectors. Because large numbers of pulses are typically required, we have interfaced the $x$-ray system with a digitizer and a microcomputer. This combination provides data acquisition that is fast, accu:ate, and amenable to immediate reduction and processing. The building blocks of the system are available commercially. System interfaces have been tailored for our needs and are a main subject of this report.

\section{EXPERIMENTAL APPARATUS}

Principal components of our system are a pulsed bremsstrahlung $x$-ray generator, a fluorescence chamber, $\varepsilon$ detector. a transient signal digitizer, and a microcomputer. In some instances the fluorescent target may be omitted and the detector positioned directly in the primary beam. Some of the system, diagrammed in 
Fig. 1, conceptually resembles its counterpart of the de system described in Ret. 1. Apart from geometric and stuctural details. a major difference is that the pulsed nature of our system requires a different lype of data recording. Also, because of antleipated lurther applications, we operated and characterized the system in air rather than in vacuum.

\section{A. Pulsed Bremsstrahlung X-Ray Source}

The instrument that generates the primary bremsstrahlung beam is a Ficld Emission Corporation* (now Hewlett-Packard) Model 7.322 x-ray pulser (fexitron). The end point of the $x$-ray energ: distribution can bo aconunuously varied from 120 to $180 \mathrm{keV}$. The $x$-ray tubes employ a conscal. tungsten anode lo generate the beam. which is limited in spatual extent by a window aperture. Euther Korar (1).(10)3-in.-thick) or bervllium (1).11-5-1n-thick) evit windows are used. depending on the desired softuess of the a-ray spectrum.

The measured beam intensity at $10 \mathrm{c}(\mathrm{m}$ is about 100 mrad/pulse and 1100 nirad/pulse when the Kovar and heryllium window tubes. respectively, are used. The

*l se . brand names or trade names dees not necessarly impli endersement by the I aherator machine operales in a single-pulse mode, with a minimum of about $10 \mathrm{~s}$ between pulses. Nominal pulse width is approximately 50 ns FWHM.

\section{B. Fluorescence Chamber}

The chamber provides a convenient platform for mounting the fluorescent foil. a filter. and a detector. Figures 2 and 3 show the verall experimental arrangement and a close-up of the target chamber, respectively. The chamber dimensions are such that only the rear wa'l (removed for most experiments) intercepts the p. inary (brensstrahlung) bean. The fluoreseent holder ' ames are also just outside that beam.

Typual foil thicknesses are about one nean free path of the fluoreseent $x$-ray. Thus, with the foil at $45^{\circ}$ to both the heam axis and the detector axis. ahout $24 \%$ of the $x$ rays generated on the far side are transmitted. This configuration permits a salisfactory compromise between signal intensity and signal-lo-scattered background ratio. Table I summarizes our set of fluorescent foils.

In addition to the seatter from the fluoreseent foil, other soure's of background are air scatter. backscatter and reradiation from the room wall (2)-(n) concrete), and leakage from the $x$-ray tube housing. Air scatter is

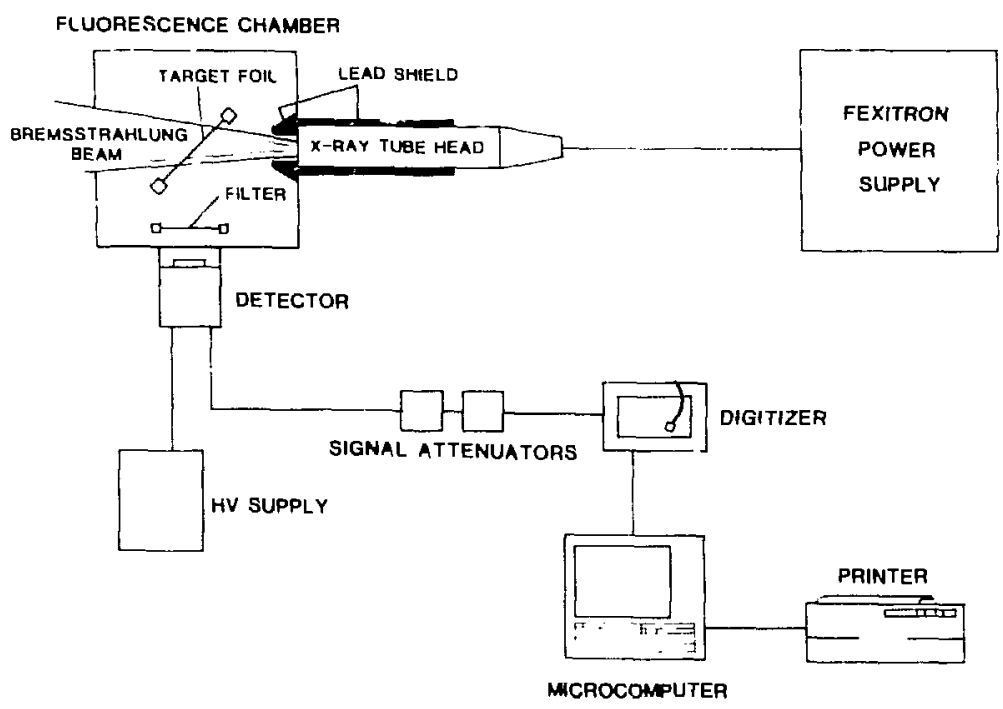

Fig. 1. Diagram of the pulsed fluorescent x-ray system. 


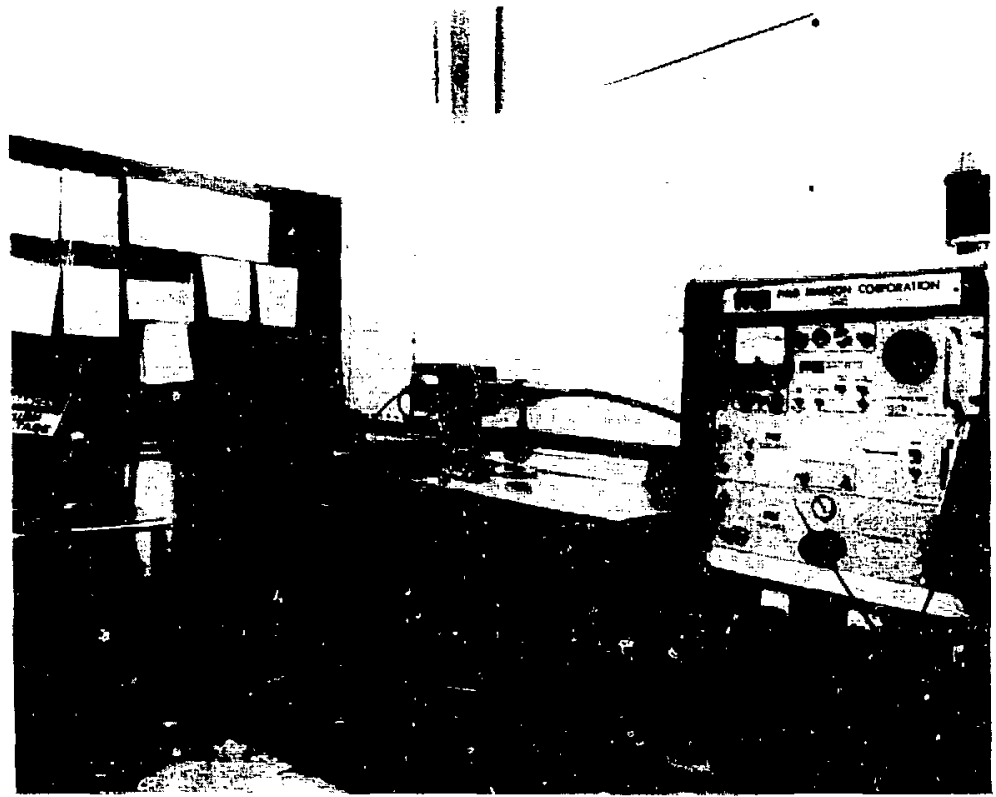

Fig. 2. Photograph of wised $x$-ray generator. The fluorescence chamber is on the lab bench in the m...d.- of the picture. The operating console is on the right, and the high-voltage unit is on the extreme left. The bremsstrahlung tube head and a detector are attached to the fluorescence box. Also visible are a detector power supply (connected to deteetor) and a spare detector at far end of bench.

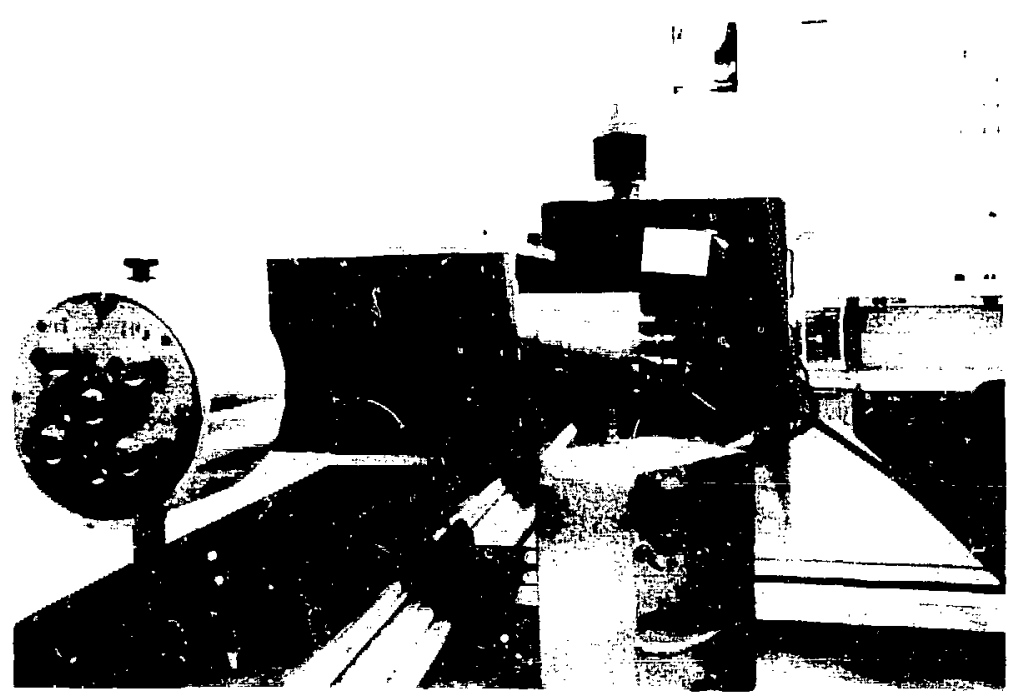

Fig. 3. Close-up view of flucrescence chamber. looking toward the tube head. A tareet foil and a filter hang from the top of the chamber. 


\begin{tabular}{|c|c|c|c|c|c|}
\hline \multirow[b]{2}{*}{ Symbol } & \multirow{2}{*}{$\begin{array}{c}\text { Material } \\
\text { Atomic No. }\end{array}$} & \multirow{2}{*}{$\begin{array}{l}\text { Thickness } \\
\left(\mathrm{mg} / \mathrm{cm}^{2}\right)\end{array}$} & \multicolumn{3}{|c|}{ X-ray energy (keV') } \\
\hline & & & $\left(k_{\mathrm{u}_{2}}\right)$ & $\left(k_{\mathrm{it}_{1}}\right)$ & {$\left[k_{\beta}\right.$ (ave) } \\
\hline $\mathrm{Ti}$ & 22 & 8.52 & 4.50 & 4.51 & 4.9 \\
\hline $\mathrm{Fe}$ & 26 & 15.9 & 6.39 & 6.40 & 7.1 \\
\hline $\mathrm{Cu}$ & 29 & 17.6 & 8.03 & 8.05 & 8.9 \\
\hline N10 & 42 & 50.5 & 17.37 & 17.48 & 19.7 \\
\hline Sn & 50 & 87.4 & 25.04 & 25.27 & 28.6 \\
\hline Gd & 64 & 128 & 42.31 & $\mathbf{4 3 . 0 0}$ & 49.0 \\
\hline $\mathbf{T a}$ & 73 & 224 & 56.28 & 57.54 & 65.7 \\
\hline
\end{tabular}

Determined by weighing sample of known area.

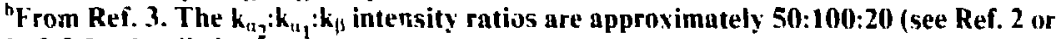
Ref. 3 for detailed values).

comparable whth that from about a mil $10.0025 \mathrm{~cm}$ of most larget materials and cannot be eliminated without "Wa uating the chatmher. The room wall. which serves as a beam stop. is far conough alway and has not posed a measurable problem. Leakage from the housing, though nceliguble in radiological terms. can contribute a significant background. I 3-mm-thick lead sleeve and a tapered avera ${ }_{2}$ : thickness about $6 \mathrm{~mm}$ ) lead collimator hatce reduced this leakage background about a hundredlivel.

\section{Detectors}

In many applications the sensor ( $\mathrm{x}$-ra) converting material) or the detector (sensor plus immediate clectronics) is the object of study or of calibration. For the exerceses cieseribed here. we used diffused junction silicon photodiudes mounted on a housing that contained the biasing electronics but no amplification. The diodes wese $150 \mu \mathrm{m}$ and $300 \mu \mathrm{m}$ thick. p-doped, and of nominally $10 \mathrm{kilohm} \cdot \mathrm{cm}$ resistivity. Full-depletion voltages were atout $45 \mathrm{~V}$ and $90 \mathrm{~V}$, respectively. Normal dark currents at room temperature were a few tens of anoamperes in the aciive element and up to $1 \mu \mathrm{A}$ in the guard ring.

One type of sensor configuration employs two diodes of dificient areas on a common silicon substrate and with a common negative side contact. A separate guard ring surrounds eact of the diodes. These sensors were made for special applications where swings in the input signals exceed the dynamic range of a single diode plus its electronics.

\section{Digitizer}

Signals from the delector (either directly from the photodiodes or from assuciated integrating and amplifying electronics) are digitized by a Transiac Model 2001 digitizer. The digitizer has a specified maximum sampling rate of $100 \mathrm{MHz}$ and a specificd analog bandwidth of $50 \mathrm{MHz}$. It is (AMAC compatible in order to interface with a microcomputer.

Functions such as sampling rate and memory size are selected through front panel controls or tas implemented in our case) through microcomputer commands. Trigger signals are obtained either directly from the fexitron monitor output or from a monitor detector in or near the beam. In either case. conditioning the trigger signal with nuclear instrumentation (NIM) modules has been helpful.

During initial experiments we found the digitizer to be extremely sensitive to electromagnetic interference from the x-ray pulser. Niost of the noise appeared to be picked up by the input ronnection on the front panel. A practical solution was to place a grounded. copper shield over the front.

\section{E. Microcomputer}

The microcomputer, an IBM Personal Computer. Model XT. performs five major tasks: (1) set up and configure the data acquisition functions, (2) test the data acquisition functions, (3) acquire and store on disk the digitized information with current information about the experimental parameters, (4) immediately analyze each pulse in real time, and (5) process and analyze the data after the experiment. 
Th. first function allows the experimenter to select and program several digitizer froni panel parameters such as the number of pretrigger samples. the sample record length. the sampling interval. and the offset voltage. The experimenter may also cnter parameters that define important properties of the experiment such as the fexitron voltage and the geometrical configuration.

The secund function allows the experimenter to verify the operation of both the data acquisition hardware and the software without actually operating the $x$-ray generator.

The third function is implemented using a Transiae Model PCOOt CAMAC crate controller that interfaces directly to the computer. A library of support routines for the controller was written to provide general highlevel language aceess and control of CAMAC devices such as the digitizer used in this experiment.

The fourth function allows the experimenter to display, in graphical lorm. both the raw digitized $\mathrm{e} x$ - perimental data and the values derived by real-time analysis of the raw data. The graphics hardware used is the Hercules Graphics Adaptor, which inuriaces direcily to the computer and provides $720 \times 350$ resolution monochrome graphics. Again, a library of support r utines was written to provide general high-level li:nguage access to the Hercules graphics hardware. The real-time data analysis consists of a combination of pulse-finding and data-fitting logic. The pulse-finding algorithm determines various characteristics of the pulse. such as the base line. start and end points. and maxinum value. The data-fitting algorithm then implements a least-squares fil of the three highest points to a parabola. The final results oblained are peak height. width, and area.

The digitizer-microcompuler part of the system is shuwn in Fig. 4. A representative hard copy output of the pulse visible in Fig. $t$ is shown in Fig. 5.

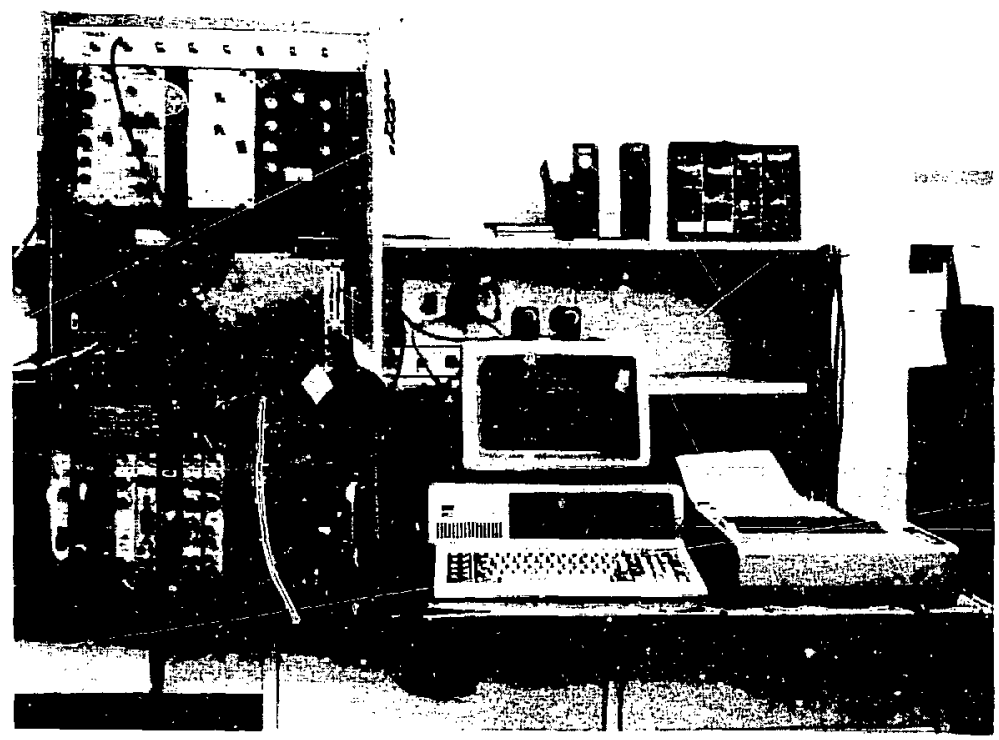

Fig. 4. Photugraph of the digitizer-microcomputer part of system. A representative cigitized pulse and other output are visible on the monitor screen and on the hard copy in the printer. The digitizer is the only module in the CAMAC crate (middle of rack). Some of the NIM modules at the boltom are used in certain experiments. The signal attenuators (top of monitor) reduce signal amplitude into digitizer winciow. 
TA861984.81?

Peak Height $=1889.5$ ure, Ared =

67843.1

Width $(1 / 4 \mathrm{Max})=.48.21 \mathrm{~ns},(1 / 2 \mathrm{Max})=34.22 \mathrm{~ns},(3 / 4 \mathrm{Max})=19.38 \mathrm{~ns}$.

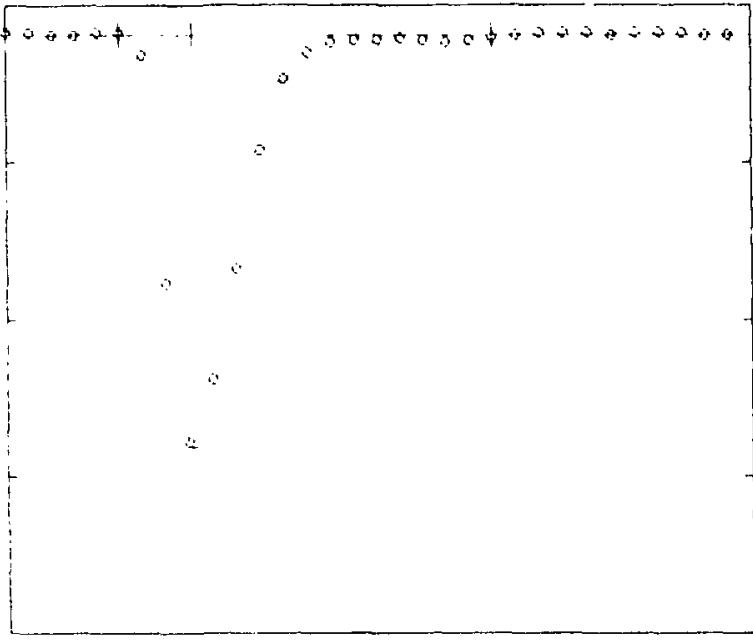

Press RETURH Key To Continue

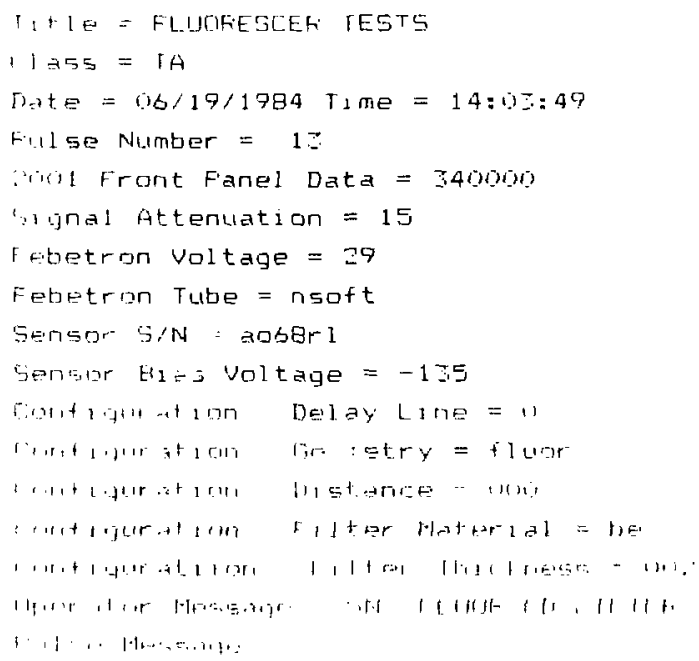

Fig. 5. Typical hard cop? output of digitied and processed signal. 


\section{SYSTEN CHARACTERIZATION}

\section{A. X-Ray Output Jitter}

Pulse-to-pulse variations in the digitized signal can arise from variations in the $x$-ray pulser output and from sampling limitations in the digitizer. In our system the former appears to be the more significant effect.

We exatmined the effect of sampling by comparing the digitized signal with that recorded on a fast oscilloscope (Tektronix 71(14). The signal from the detecior was split by a matched " $T$ " and simultaneously recorded with the two instruments. The results, compared in Table II. show the diflerences to be about equal to the reading error on the seope trace.

Pulse-to-pulse jitter of the bremsstrahlung beam is illustrated in Table Ill. The spread about average values is about lwict as large as differences between the readings from digital and analog records. The data in Table 111 were recorded with the digital system. An "nld" $(\geq 15,000$ pulses) $x$-ray tube was used in the fexitron when these data were recorded, so that "worst case" rather than "lypical" variations are shown

Note that the pulse width given in Table III differs from that in Table 11 and also from the nominal specification of 50 ns. Narrower pulses arise when the soft $x$ ray component in the primary beam is tiltered out. We attribute the $-7(1)$-ns width in Tatte $I 1$ to an old $x$-ray tube. Wider pulses ealat also result when the detector response lime is long and must be convolved with the $x-$ ra! pulse.

We have not observed a significant difference in jitter as a function of pulse width. We have also lonked tor any dependenec of jitter on machine paraneter., such as charging voltuge. and on operating procedures. such as unce delay between charging and firing. There appears to be little effect as iong as operation is confined to

TABI.F. II. Comparison Beth sen Digital and Analog Records of Same .-Ray Fluorescence Pulse

\begin{tabular}{lllll}
\hline Height & & \multicolumn{3}{c}{ Width at \% of Height (ns) } \\
\cline { 3 - 5 } Pulse No. & $(\mathrm{mV})$ & $25 \%$ & $50 \%$ & $75 \%$ \\
\hline 1 digita! & 352.5 & 87.2 & 69.8 & 52.6 \\
1 analog & 348 & 85 & 71 & 53 \\
2 digital & 350.1 & 86.5 & 71.7 & 54.6 \\
2 analog & 348 & 86 & 71 & 54 \\
3 digital & 349.1 & 89.6 & 73.6 & 55.5 \\
3 analog & 348.0 & 86.0 & 72.0 & 55.0 \\
\hline ave. dif. & 2.6 & 2.1 & 1.2 & 0.5 \\
(\%) & 0.7 & 2.4 & 1.6 & 0.9 \\
\hline \hline
\end{tabular}

\begin{tabular}{|c|c|c|c|}
\hline \multicolumn{4}{|c|}{$\begin{array}{l}\text { TABLE III. Representative Variations in } \\
\text { lung Pulse Characteristics" }\end{array}$} \\
\hline Pulse No. & $\begin{array}{c}\text { Height } \\
(\mathrm{mV})\end{array}$ & $\begin{array}{l}\text { Width at } \\
50 \% \text { of } \\
\text { Height } \\
\text { (ns) }\end{array}$ & $\begin{array}{c}\text { Area } \\
(\mathrm{mV} \cdot \mathrm{ns})\end{array}$ \\
\hline I & 416.5 & 24.8 & 11248 \\
\hline 2 & 431.3 & 27.1 & 12348 \\
\hline 3 & 407.1 & 26.3 & 11638 \\
\hline 4 & 422.8 & 24.4 & 11448 \\
\hline 5 & 436.0 & 25.1 & 11996 \\
\hline 6 & 402.7 & 26.8 & 11502 \\
\hline average & 419.4 & 25.7 & 11696 \\
\hline std. dev. $(\%)$ & 3.1 & 4.4 & 3.5 \\
\hline
\end{tabular}

"Pulses were? generated with an old tube. Variations are more representative of "worst case" rather than "typical" condition.

specified parameter ranges and recommended procedures. A noticeable twofold to threefold improvement in jitte: resulted when the old tube was replaced with a new one. The pulse width also decreased.

\section{B. Beam Intensity and Spatial I niformity}

1. Primary Beami. The dose in the primany beam was directly measured with thermoluminescent dosimeters (TLDs) for both the beryllum and the Kovar window tubes. The respective dose on axis and $10 \mathrm{~cm}$ from the tuber was about $1100 \mathrm{mrad}$ and about $100 \mathrm{mrad}$ per pulse at $150 \mathrm{keV}$ end point. The reading for the beryllium window tube is probably low because of the known falloff in TLD responsets to $x$ rays of energy below $20 \mathrm{keV}$. The equivalent dose dediced from silicun sensor response is som: what higher tabout 2400 and $400 \mathrm{rad}$ prr pulse from the hard and soft tubes. respectively). We have been unable to reconcile these differences.

The beam intensity follows the inverse square law for distances greater than about $10 \mathrm{~cm}$ from the window. It is. however. affected by air absorption. The effective source position. located by triangulation from multiple pinhole images, was found to be $5.8 \mathrm{~mm}$ behind the beryllium and $3.7 \mathrm{~mm}$ behind the Kovar window. At distances closer than $10 \mathrm{~cm}$, effects of source geometry are no longer negligible. The source diameter, measured with a pinhole image, is $-4 \mathrm{~mm}$. Furthermore, the source spot is shaped like a "donut." a consequence of the arrowhead shape of the anode. A photograph of a pinhole image is shown in Fig. 6. 


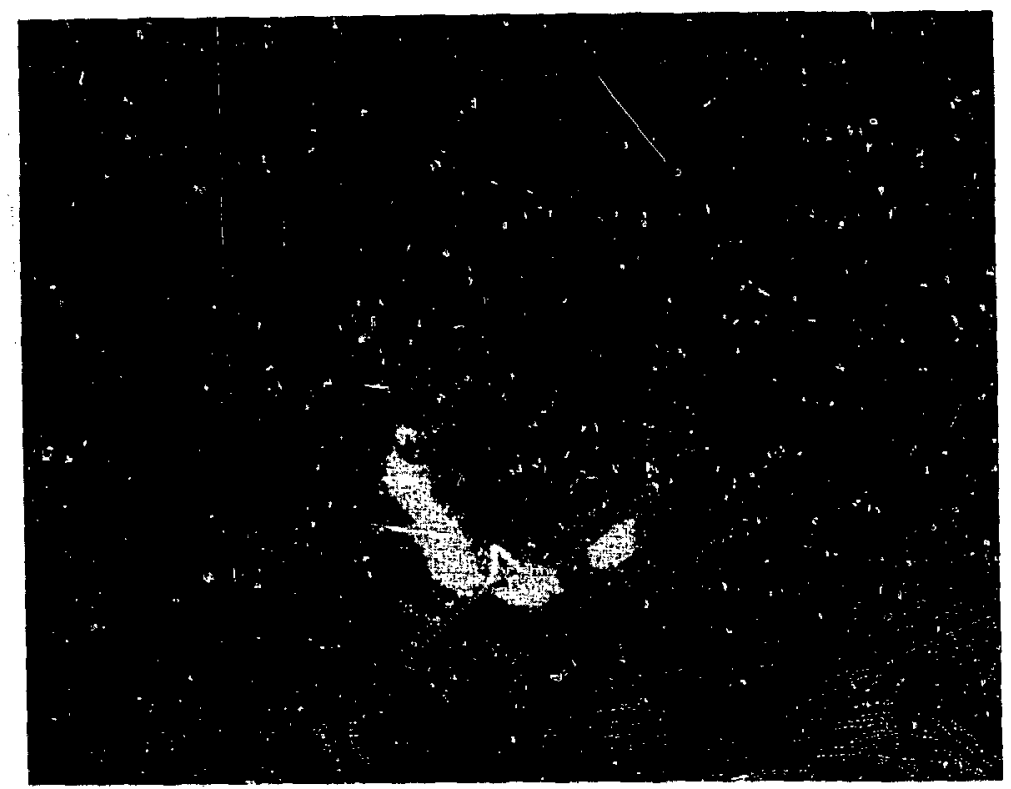

Fig. 6. Phothgraph of pinhole image of bremsstrahlung source. The image was recorded through a $0.5-\mathrm{mm}$-diam pinhole and with a magnification of $6 . \mathrm{An}$ optically fluorescent sereen was pressed against the film to increase sensitivity. vole the struclure in the - t-mm-diam source.

Because the extreme tip of the anode cone is not illuminated by electrons. The spatial distribution is affected as well. Figure 7 shows a series of film exposures by the direel beam at various distances from the tube. Note the penumbra effects in the center of the beam at clese distances. We assume these result from shadowing b! the anode lip.

2. Fluorescent Beam. The fluorescent foil interecpts the entire beam and hecomes an extended source. averaging out spatial variations in the primary beam. Film placed in the detector plane was uniformly exposed at all fluorescent energies.

The intensity of the fluorescent bean at the detector plane $(10 \mathrm{~cm}$ from the intersection of the primary beam axis and the detector axis) was determined with the diffused iunction silicon detectors described in Sec. II.C. The time- honored assumption about linearity of silicon photodiodes. at least at these levels. appears supported by some of our results and by other data.' The measured values, interpreted with the aid of cross-section data' is $\mathrm{eV} / \mathrm{cm}^{2}$ pulse, are given in Table IV. The generally accepted value of $3.6 \mathrm{eV} / \mathrm{c}$ was used for the cnergy-tocharge conversion factor of silicon.

\section{Beam Purity}

The ratio of the fluorescent $x$-ray intensity to the background is probably the most important single parameter and for a pulsed source is also the most difficult in measure accurately because, with a puised system such as this. it is not possible to count and sort individual photons as with de systems.' We therefore relied on the data in Ref. 1, where applicable, to be the asymptote for any of our determinations. We cstimated the scatlered background fraction in the recorded signal as follows. A nonfluorescing. dummy target made of polyethylene was substituted for the metal foil. The areal density of the plastic was selected to approxinately match that of the particular fluorescer. Firstorder corrections to the signal from the dummy target were based on the densily differences.

The fluorescent yield of carbon and hydrogen is known to be very small." "The resulting $x$ rays are of such low energy $(<0.3 \mathrm{kcV})$ that they are absorbed by intervening air and the 0.05 - $\mathrm{mm}$-lhick beryllium filter normally in front of the sensor. The cross section for Compton scattering changes slowly from 1 to $200 \mathrm{keV}$ and with atomic number of the target. We did not 


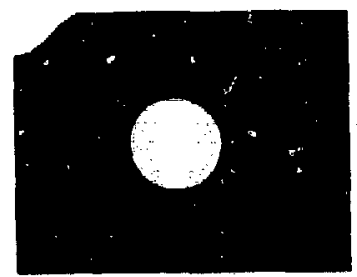

d. $\operatorname{sen}$

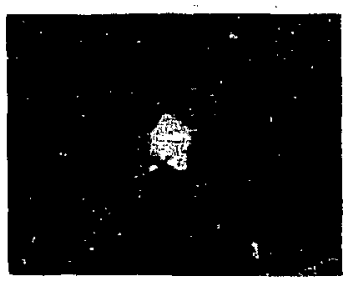

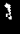

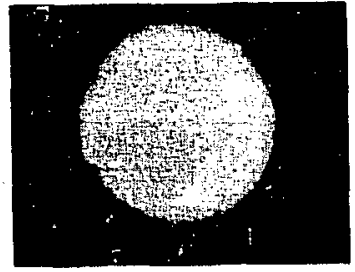

a. It

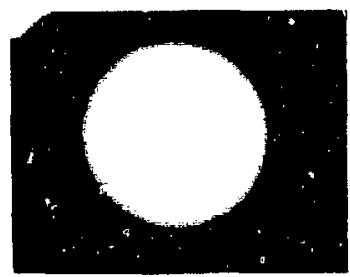

Fig. 7. Film exposure in primary beam at four distances from tube window. Note the structure in the beam arising from source geomety.

correct for these changes. partly because the primary spectrum is a continuum ard partly because the correction is a small part of the background, which itself is a smiall part of the total signal. Some compensation for the scaltering cross-section differences occurs because those $x$ rays scattered by air on the far side of the target and by the far side of the target itself are more visible to the sensor thro'igh the polyethylene than through the metal foils.

We next verified that a filter placed in front of the detector redured the signal according to tabulated cross sections. Whenever possible, filter sets wire chosen to include filters whose K-edges were just below and just above the energy of the fluorescent $x$ ray. These results are summarized in Table $V$.

\begin{tabular}{|c|c|c|}
\hline Target & $\begin{array}{l}\text { Fluorescent Signal Amplitude } \\
\text { - TotaI Signal Amplitude }\end{array}$ & $\begin{array}{l}\text { Purity (rad) } \\
\text { (from Ref. 1) }\end{array}$ \\
\hline $\mathrm{Ti}$ & 0.77 & $\mathbf{a}$ \\
\hline $\mathrm{Fe}$ & 0.93 & a \\
\hline $\mathrm{Cu}$ & 0.94 & 0.987 \\
\hline Mo & 0.94 & $\therefore .981$ \\
\hline Sn & 0.88 & $0.976^{b}$ \\
\hline Gd & $0.76^{c}$ & 0.955 \\
\hline $\mathbf{T a}$ & $0.58^{\mathrm{c}}$ & $0.90^{\mathrm{b}}$ \\
\hline
\end{tabular}

Von data given for $Z<29$.

hInferred from data for nearby elements.

'Includes contribution from $L x$ ray. 
Some details in Table $\mathrm{V}$ need to be addressed further. Agreement between the two sets of data appears reasonably good for $Z<50$. The differences most probably arise from differences in experimental conditions, most notably spectral integratior vs pulse height analysis. In the case of the higher $Z$ targets, the primary-beam energy is a factor as well. All our data were taken with a primary-beam end point of $150 \mathrm{keV}$. In Ref. I, data for copper and molybdenum were taken with $100-\mathrm{keV}$ end points and for the others with 300-keV end points. Furthermore, target thicknesses (and presumably material ptirities) were not the same. Our targets tended to be thinner. which wnuld improve the fluoreseence/scatter ratio. but decrease the signal relative to nontarget background.

Because we have achieved nearly the purity given in Ref. I for copper and molybdenum, we believe our data for iron and titanium to be valid also, perhaps with a similar 3-5\%, difference. Extrapolation from other data in Ref. I supports that conclusion.

Regarding elfects of primary-beam end-point energy. we observed a trend that agreed with the dependen $e$ reported in Ref. I. In general the fuorescent signal was cleaner with lower generator volt $\tilde{a}_{1}$ 'es for lower $Z$ targets and with higher voltages for higher $Z$ targets. Qualitatively, this difference reflects the tradeoff between higher photoelectric cross sections for the lower energy primary photons and the necessity for the primary photons to have an energy greater than the K-shell hinding energy of the target. For example, with the titanium target. our fluorescent signal fraction increased by about $3 \%$. whereas with the tantalum target, it $d c$ ireased by about $10 \%$ as the primary beam end-point encrgv was raised from $120 \mathrm{keV}$ to $180 \mathrm{keV}$

We also observed a $Z$ and energy dependence in the data treatment. Namely, the fluorescent fraction determined by using signal a mplitudes differed by as much as $10 \%$ from that determined from integrated signals. For low- $Z$ targets there was little difference, the integral showing a $1-3 \%$ higher fraction. For the higher $Z$, on the other hand, values deduced from integrated signals tinded to be $8-10 \%$ lower than those from signal ampititudes. We believe that this phenomenon arises from details iclated to the pulse structure and pulse generation. Since the machine discharge does not result in a perfect square wave of voltage vs time, there is necessarily a time dependence in the primary-beam spectrum, with an associated spectral dependence of beam purity.

\section{EXAMPLES OF APPLICATIOUS}

A. Linearity Measurements ystem (without usigg the fuorescent feature) to transfer curve measurements. Figure 8 shows the response of a silicon photodiode as a function of incident intensity, controlled by $/ / \mathrm{r}^{2}$ dependence. Note the saturation of the signal amplitude-a function of the biasing and the electrical load. The integral of the signal, on the other hand, remains linear over the range of this measurement. (The departure from unity slope is accounted for by air transmission.) This somewhat trivial example illustrates the usefulness and ease of the digital system. compared with at least one alternative-that of reading film records of a scope trace.

\section{B. Crosstalk Between Sensor Elements on a Common Substrate}

Figure 9 shows the signal transfer curve of the smaller of the two diodes (1.3 $\mathrm{mm}$ diam and $16.2 \mathrm{~mm}$ diam) of

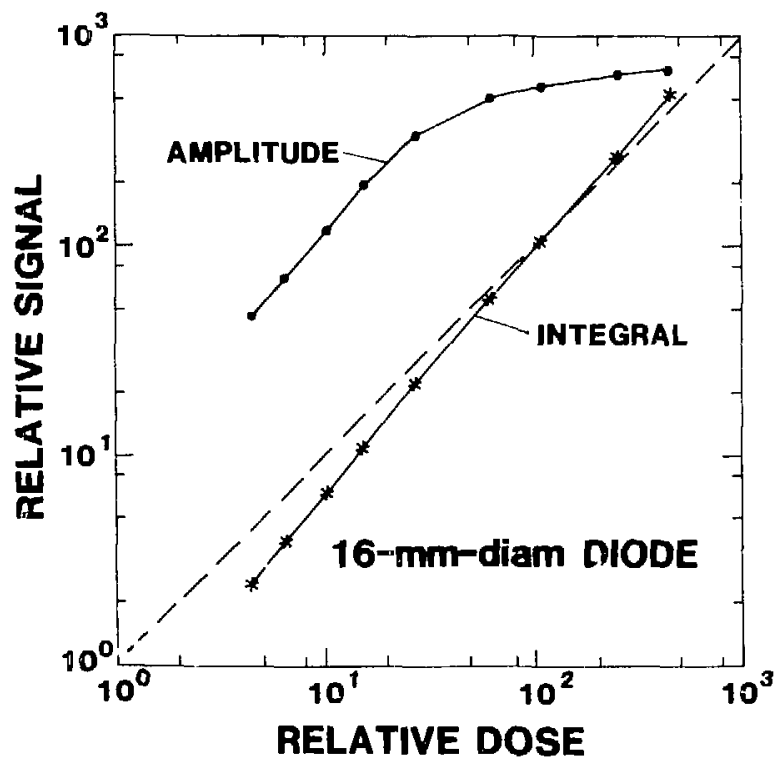

Fig. 8. Exariple of system application to transfer ctrve measurements. 


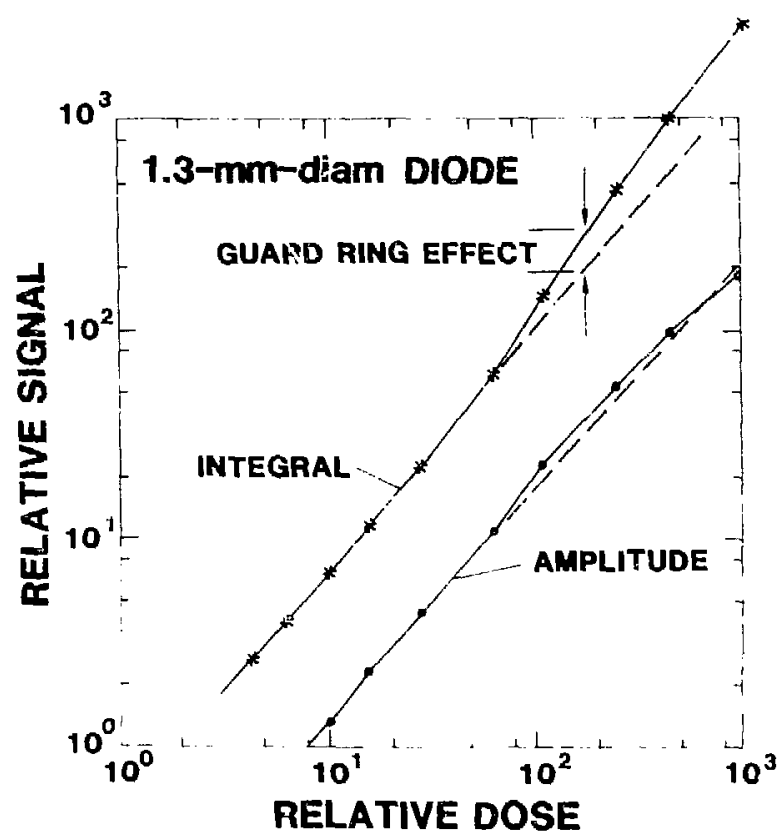

Fig. 9. Example of sistem application to identification of erosstalk among silicon clements on a common substrate.

the special sensor described in Sec. II.C. The hiasing circuitry includes 50 -ohn loads on the luw side of the in: aclive arcas and an -3-kilohm isolation between the guard rings and ground.
Note in Fig. 9 that both the $-l_{2}$ nal amplitud: and the integral increase in a superlinear Inanner above a reiative dose of about 70 . At this point the guard rings and the larger area diode are all drawing sufficient currents to change the voltage drop across the respective junctions. The resulting distortion of the electric field within the crystal produces a net funneling of extra electrons into the smaller diode, with an attendant "anomalous" increase in its signal.

Notic turther that the increase in the integral is greater than that in the signal amplitude, the latter increase being barely perceptible. The digital system has again proved very useful in identifying this ditference and in parametric tracking of performance.

C. Signal Dependence on Angle of Incidence and on Energy

As a third example we show the effect of incident angle on signal at various energies. For simple geometries such an effect can be readily calculated. However, in this case the detector uses a spherical filter in front $a^{r}$ a silicon photodiode. The results are plotted in Fig. 10. such information is important in unfolding data from continuum-emitting sources.

\section{Pulse Width Measurements}

A pulse width measurement is one of the standard tuisks of the system software. One example of its application is illustrated in Table VI. which compares pulse

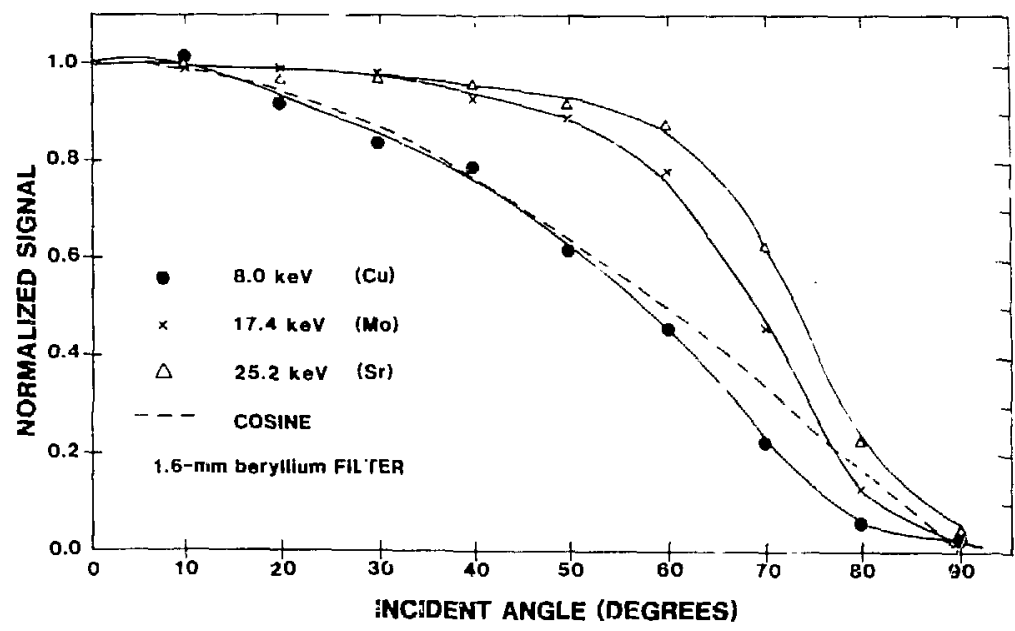

Fig. 10. ${ }^{\wedge}$ asurement of the detector response as a function of angic of incidence and or ancident $x$-ray energy: 


\begin{tabular}{|c|c|c|}
\hline Target & $\begin{array}{c}\text { K X-Ray Energy } \\
\text { (keV) }\end{array}$ & $\begin{array}{c}\text { Pulse Width } \\
50 \% \\
\text { of Peak Height } \\
\text { (ns) }\end{array}$ \\
\hline $\mathrm{Ti}$ & 4.5 & 50.9 \\
\hline $\mathrm{Fe}$ & 6.4 & 51.3 \\
\hline $\mathrm{Cu}$ & 8.0 & 49.5 \\
\hline Mo & 17 & 39.6 \\
\hline Sn & 25 & 36.8 \\
\hline Gd & 48 & 33.3 \\
\hline $\mathrm{Ta}$ & 57 & 31.3 \\
\hline
\end{tabular}

widths observed with the various fluorescing foils. A secoind example involves the examination of the light output decay from various scintillators, including plastic, $\mathrm{CsI}(\mathrm{Tl}), \mathrm{ZnS}, \mathrm{CaWO}_{4}$, and $\mathrm{Gd}_{2} \mathrm{OS}$. The decay of these ranges from nanoseconas to nearly a millisecond. Data from all of these were captured following commands to the microcomputer to adjust sampling interval and window width as needed.

\section{CONCLUDING COMMENTS}

Our pulsed fluorescent $x$-ray system is proving to be very useful in several applications that require measurement of relative responses. Absolute measurements of such fluorescent $x$-ray intensities are very difficu't to make-a generally recognized and acknowledged faci. A goal for upcoming work is to measure these more accurately, ideally by improving existing techniques and by adding corroborative ones.

The digitizer-microcomputer aspect of the system has proved to be at least as useful as anticipated. A goal in this area is to expand the data-processing capabilities by (1) adding custom routines for specific applications and (2) adapting routines such as least-squares algorithms, fast Fourier transforms, etc., to our library.

A parallel effort has been undertaken to assemble a code to calculate results for a variety of experimental configurations. Once developed, this tool should be useful for optimizing experiments and for identifying errurs. Results to date are encouraging, but first-order discrepancies sugge', that considerable additional effort will be needed.

\section{ACKNOWLEDGMENTS}

We are grateful to L. E Pryant and J. P. Lucero for the loan of their fexitron and tc them and to $J$. Fowvler and H. Cowhere for discussions regarding texitron performance and properties.

We thank R. W. Higgins, E. Kiemle, and J. E. Serna for help with design and fabricntion of mechanical accessories, and we thank S. F. Hahn and A. C. Rose for help with electronics-related problems.

We appreciate the assistance of $H$. E. Felthauser, S. A. Davis. R. W. Davis, E. C. Torres, J. W. Gutierrez, R. W. Martin, D. W. Lier, K. M. Gliber, and Y. Y. Eisen for valuable disclissions and help with characterization of our system.

We thank W. R. Scar'ett, i. R. Asbridge, and E. R. Tech for their irterest in this project and for thcir continuing supjort and encourgement.

\section{REFERENCES}

1. E. Storm, "Bremsstrahlung-Induced K-Fluorescenrc." Los Alamos Scientific Laboratory report LA-6072 (September 1976). and references cited iherein.

2. E. Storm and H. I. Israel, "Phcton Cross Sections from 0.001 to $100 \mathrm{MeV}$ for Elements 1 through 100." Los Alamos Scientific Laboratory report LA-3753 (June 1967).

3. C. M. Lederer, J. M. Hollander, and 1. Perlman, Table of Isotopes, 6th edition (John Wiley \& Sons, Inc.. New York. 1968).

4. T. J. Morgan and L. Brateman, "The Energy and Directional Response of Harshaw TLD-100 Thermoluminescent Dosimeters in the Diagnostic X-Ray Energy Range," Health Fhysics 33, 339 (1977).

5. T. O. Marshall, R. J. Pattison, A. Twyman, H. E. Preston, and J. C. Stewart, "The Performance of the NRPB Thermoluminescent Dosimeter," Nuclear Instruments and Methods 175, 147 (1980).

6. "Flash Radiography," Hewlett-Packard Co. Technical Bulletin B-23 (1973).

7. "Silicon Photodiode Application Notes," EG\&G Electro Optics Division Applications Note D3000C-2 (1979). 